\title{
Photodegradable tissue-adhesive hydrogels
}

\author{
Maria Villiou, ${ }^{\dagger *}$ Julieta I. Paez ${ }^{\dagger *}$ and Aránzazu del Campo ${ }^{\dagger *}$ \\ $\dagger$ INM - Leibniz Institute for New Materials, Campus D2-2, 66123, Saarbrücken, Germany. \\ † Saarland University, Chemistry Department, 66123 Saarbrücken, Germany. \\ Corresponding authors: julieta.paez@,1eibniz-inm.de; aranzazu.delcampo@,leibniz-inm.de
}

KEYWORDS: photodegradable hydrogel, catechol-mediated crosslinking, bioinspired hydrogel, tissue adhesive

\begin{abstract}
:
Hydrogels for wound management and tissue gluing have to adhere to tissue for a given time scale and then disappear, either by removal from the skin or by slow degradation in applications inside the body. Advanced wound management materials also envision the encapsulation of therapeutic drugs or cells to support the natural healing process. The design of hydrogels that can fulfil all these properties with minimal chemical complexity, a stringent condition to favor transfer into a real medical device, is challenging. Herein, we present a hydrogel design with moderate structural complexity that fulfils a number of relevant properties for wound dressing: it can form in situ and
\end{abstract}


encapsulate cells, it can adhere to tissue, and it can be degraded on demand by light exposure under cytocompatible conditions. The hydrogels are based on starPEG macromers terminated with catechol groups as crosslinking units and contain intercalated photocleavable triazole nitrobenzyl groups. Hydrogels are formed under mild conditions (HEPES buffer with 9-18 $\mathrm{mM}$ of sodium periodate as oxidant) and are compatible with encapsulated cells. Upon light-irradiation, the cleavage of the nitrobenzyl group mediates depolymerization, which enables on-demand release of cells or debonding from tissue. The molecular design and obtained properties are interesting for the development of advanced wound dressings and cell therapies, and expand the range of functionality of current alternatives.

\section{Introduction}

Hydrogels are hydrophilic networks with the ability to uptake and retain large amounts of water, body fluids or relevant therapeutic molecules. As soft and hydrated networks, hydrogels share a fundamental similarity with the natural scaffold of living tissues, and fulfil minimum requirement for protecting them. This property makes hydrogels the material of choice for wound dressings, tissue adhesives or sealants. As depots, non-toxic hydrogels are fundamental components of therapeutic devices, loaded with drugs or cells to be delivered in the body, and support healing processes. For this purpose, in situ forming hydrogels are preferred since they can be easily applied or injected into therapeutic sites. A variety of chemical and physical gelation mechanisms are available for this purpose..$^{1-3}$ 
For application as wound dressings or tissue adhesives, hydrogels also need to adhere to tissue for a given time scale, and then be either removed at a given time point (i.e. replacement of a wound dressing) or gradually disappear by degradation (i.e. for controlled drug release or during tissue regeneration). These two requirements are contradictory to some extent, and have challenged chemists to expand the toolbox of chemical reactions and their combination for the design of advanced hydrogel formulations. ${ }^{4-5}$ Adhesion to tissue in commercial medical devices largely relies on electrostatic interactions with charged polymers, for example alginate (e.g. Algisite ${ }^{\circledR}$, Smith \& Nephew) or polyacrylate (UrgoClean ${ }^{\circledR}$, Urgo). Protein-based natural recognition motifs are also exploited, for example in fibrin glue (e.g. Tisseel®, Baxter). Other systems take advantage of covalent reactions between isocyanates (TissuGlu ${ }^{\circledR}, \mathrm{B}$. Braun), Nhydroxysuccinimide (NHS) esters (CoSeal ${ }^{\circledR}$, Baxter; DuraSeal ${ }^{\circledR}$, Integra LifeSciences), or aldehydes (BioGlue ${ }^{\circledR}$, Cryolife) with proteins in natural tissue. On the academic side, musselinspired catechol chemistry has been largely explored for tissue adhesion, ${ }^{6-8}$ sealing, ${ }^{9-10}$ as hemostatic agents ${ }^{11}$ or wound dressings. ${ }^{12-13}$ This chemistry has also been transferred to mediate adhesion of hemostatic pads (InnoSEAL ${ }^{\circledR}$, InnoTherapy). The catechol group has many different reaction possibilities and partners in a natural environment ${ }^{14}$ and provides a generic solution for a wide range of application scenarios. ${ }^{15-16}$

Approaches for one-step removal of hydrogels mostly rely on temperature ${ }^{17}$ or $\mathrm{pH}^{18}$ responsive physically crosslinked polymeric backbones, or on the addition of soluble competitors that disrupt covalent bonds within the macromolecular chain. ${ }^{19}$ Gradual removal is typically achieved introducing hydrolytically ${ }^{20}$, enzymatically ${ }^{21}$ or light $^{22-24}$ cleavable units in the network. Photodegradable hydrogels enable the easiest and most precise regulation of the depolymerization kinetics, which can be one-step or gradual just by controlling the external 
exposure dose. ${ }^{25}$ The depolymerization reaction occurs by the photochemical reaction of photocleavable groups intercalated in the network structure, in most cases derivatives of the nitrobenzyl moiety. ${ }^{25-27}$ Envisioned application scenarios of these systems include photodegradable bariatric balloons and esophageal stents, ${ }^{28}$ light-regulated hydrogels for therapeutic release of drugs, ${ }^{29-30}$ bacteria ${ }^{31}$ or mammalian cells ${ }^{26,32}$ for regenerative medicine.

Recently, a photoremovable hydrogel has been commercialized as skin adhesive (Lumina ${ }^{\mathrm{TM}}, \mathrm{CE}$ marked). ${ }^{33}$ Additionally, chitosan and NHS-terminated polyethylene glycol (PEG) hydrogels containing nitrobenzyl groups have been explored as in situ forming and photodegradable hydrogels that can adhere to skin tissue and be used for wound management. ${ }^{34}$ However, no encapsulation studies in such systems were reported. Herein, hydrogels based on starPEG macromers terminated with self-polymerizing and tissue adhesive catechol groups as well as containing photocleavable triazole nitrobenzyl units are presented (Figure 1A). These hydrogels can crosslink in situ, attach to wet skin and photodegrade on-demand under cytocompatible conditions (Fig. 1B). Moreover, the obtained systems are cytocompatible and can encapsulate cells and release them on demand. Our findings expand the functionality of previously reported systems $^{35-36}$ for application scenarios in advanced wound management.

\section{Results and Discussion}

Synthesis of PEG-NBt-c

The photodegradable hydrogel precursors used in this work are derivatives of 4-arm PEG (10 and $20 \mathrm{kDa}$ ) with adhesive and crosslinkable catechol end-groups, and intercalated 
dialkoxynitrobenzyl triazole photocleavable units (Figure 1A). The nitrobenzyl group shows acceptable photoefficiency and cytocompatibility in vitro and in vivo. ${ }^{23,28}$ The nitrobenzyl triazole (NBt) variant was preferred $v s$. the ester linkage used elsewhere (NBe, Figure S2) 27, 29, 37 in order to improve the hydrolytic stability of the polymer. ${ }^{25} \mathrm{NBt}$ was synthesized by reaction of alkyne-terminated PEG with a nitrobenzyl intermediate functionalized with an azide group via $\mathrm{Cu}(\mathrm{I})$-catalyzed azide-alkyne cycloaddition (Figure 1C). This strategy was inspired in the solidphase peptide synthesis of 4 -substituted $N \mathrm{H}-1,2,3$-triazoles ${ }^{38}$. The catechol (c) unit was introduced by end-functionalization of the chains via reaction with hydrocaffeic acid. The reaction conditions for each step were optimized to obtain moderate to excellent yields (4797\%). Final PEG-NBt-c macromers were obtained in $0.25 \mathrm{~g}$ scale with $61 \%$ yield. End-group functionalization degrees were $>85 \%$ (quantified by ${ }^{1} \mathrm{H}-\mathrm{NMR}$ ). The synthetic protocols and structural characterization of intermediate compounds and final product are detailed in the Supporting Information.

The hydrolytic stability of PEG-NBt-c solutions in HEPES buffer at $\mathrm{pH} 7.5$ after 8 days in the dark was tested by MALDI-TOF and HPLC analysis (Figure S3A). For comparison, the analogue derivative with ester linkage (Figure S3B) was also monitored. A 3\% hydrolysis occurred in the triazole linked precursor, while $12 \%$ hydrolysis was observed in the ester linked one. The stability of the polymeric chain is important to prevent premature and uncontrolled degradation of the hydrogel, ${ }^{37}$ and the nitrobenzyl triazole is better candidate than the widely used nitrobenzyl esters ${ }^{27}$ from this perspective. 


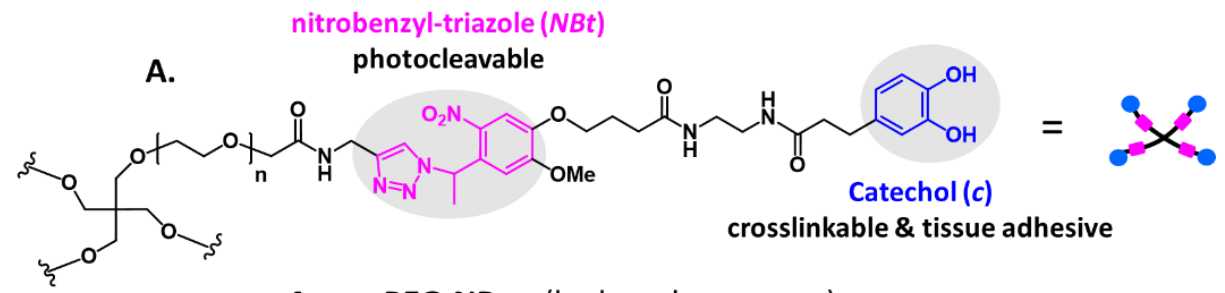

4-arm PEG-NBt-c (hydrogel precursor)
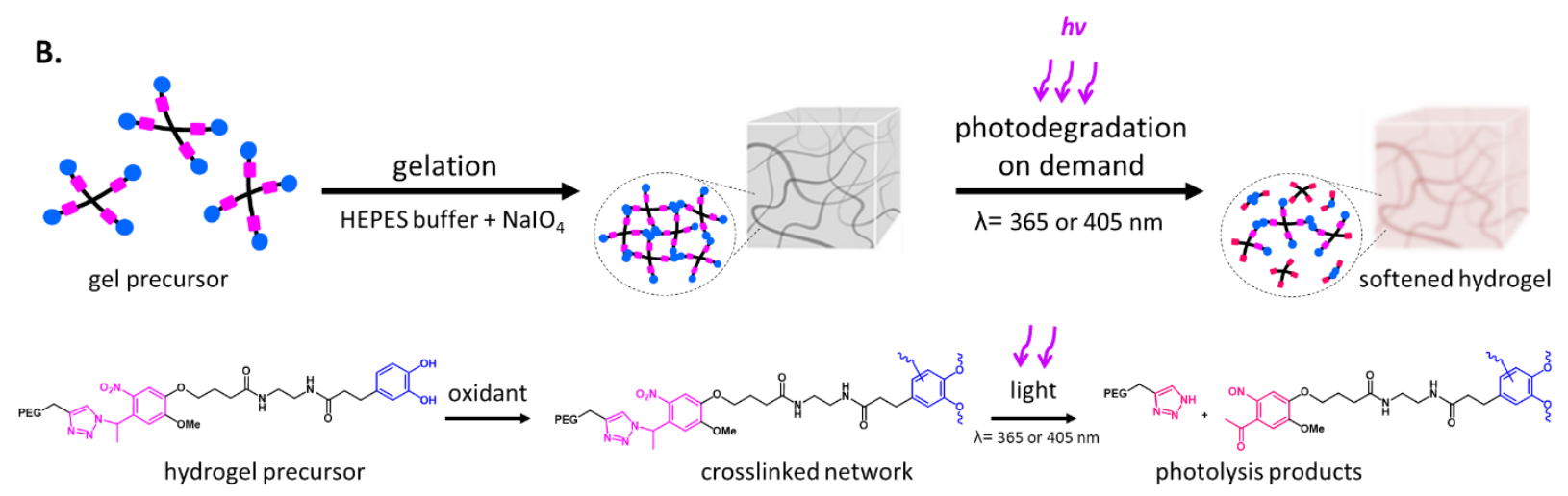

C.
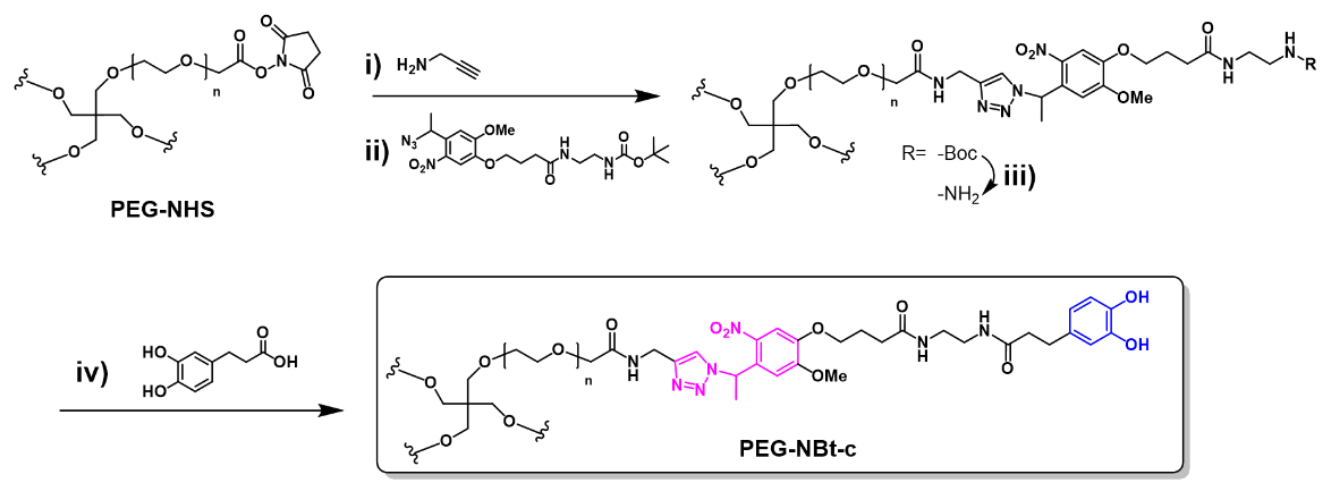

Figure 1. A) Chemical structure of the photodegradable gel precursor PEG-NBt-c. B) Hydrogel formation and photodegradation. The corresponding chemical reactions are indicated. C) Synthetic steps to obtain PEG-NBt-c precursor. Reagents and conditions: i) $N$-methylmorpholine (NMM), dry $N, N$-dimethylformamide (DMF), $\mathrm{N}_{2}$, room temperature, overnight; ii) CuI, sodium ascorbate, 2,6-lutidine, $N$-Methyl-2-pyrrolidone (NMP):water (4:1), room temperature, overnight; iii) trifluoroacetic acid (TFA):water (95:5), room temperature, $1 \mathrm{~h}$; iv) 3-[Bis(dimethylamino)methyliumyl]-3H-benzotriazol-1-oxide hexafluorophosphate (HBTU), $N$-Hydroxybenzotriazole (HOBT), $N, N$-diisopropylethylamine (DIPEA), $\mathrm{N}_{2}$, dry DMF, room temperature, overnight. 


\section{Photochemical properties}

The photochemical properties of the macromer were studied. The photolysis of a $1 \mu \mathrm{M}$ PEGNBt-c solution in water upon irradiation at $365 \mathrm{~nm}\left(1.2 \mathrm{~mW} \mathrm{~cm}{ }^{-2}\right)$ for increasing times was followed by UV/Vis spectroscopy (Figure 2A). The characteristic spectral changes during photolysis of nitrobenzyl derivatives ${ }^{39}$ were observed: a decay of absorbance at $\lambda_{\max }(365 \mathrm{~nm})$ due to the consumption of the nitrobenzyl group and the increase in absorbance at wavelengths $>400 \mathrm{~nm}$ associated to the formation of nitrosobenzyl ketone photolysis product. The clear isosbestic points of the UV spectra $(\lambda=340$ and $380 \mathrm{~nm})$ at increasing exposure dose indicate that no secondary reactions occur. In order to confirm the identity of the photoproducts, we analyzed the photolysis of a low molecular weight analogue (Figure 2B) by mass spectrometry. The release of nitrosobenzyl ketone $(\mathrm{m} / \mathrm{z}=194.0$ for $\mathrm{M}+\mathrm{H})$ and the triazole $(\mathrm{m} / \mathrm{z}=156.0$ for $\mathrm{M}+\mathrm{H})$ as photolysis products was confirmed, in agreement with previously reported data. ${ }^{38}$ We evaluated the photolysis efficiency of the nitrobenzyl triazole moiety by comparing it with the frequently used nitrobenzyl ester ${ }^{27}$ and with a nitrophenyl ethyl amide analog, previously reported by our group as photocleavable catechol derivative ${ }^{40-41}$ (Figure S4A-B). The consumption rate of the starting molecule was analyzed at increasing exposure times by HPLC (Fig. S4C). The nitrobenzyl triazole showed similar photolytic efficiency than nitrobenzyl ester and much higher efficiency than the nitrophenyl ethyl analogue under same experimental conditions. $60 \mathrm{~min}$ light exposure (dose $=4.3 \mathrm{~J} \mathrm{~cm}^{-2}$ ) lead to $99 \%$ photolysis conversion in the nitrobenzyl triazole polymer $v s .95 \%$ and $51 \%$ for the nitrobenzyl ester and nitrophenyl ethyl amide variants, respectively. These photolysis studies complement previous results by Nielsen et al on the characterization of nitrobenzyl triazoles. ${ }^{38}$ The better hydrolytic stability and the clean 
and comparably efficient photolysis of nitrobenzyl triazole make it an interesting alternative to nitrobenzyl esters for the preparation of photodegradable hydrogels.

A.

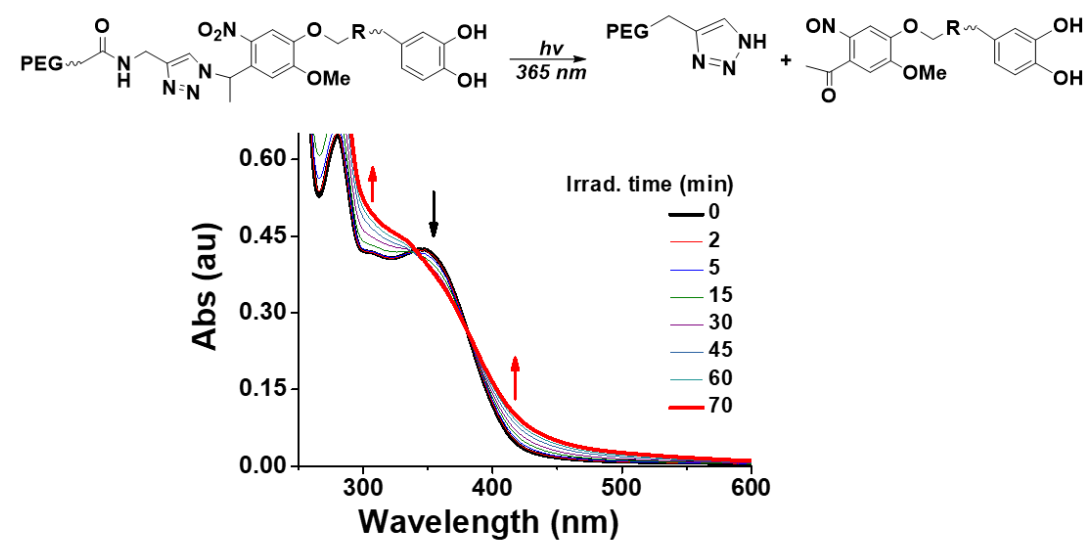

B.

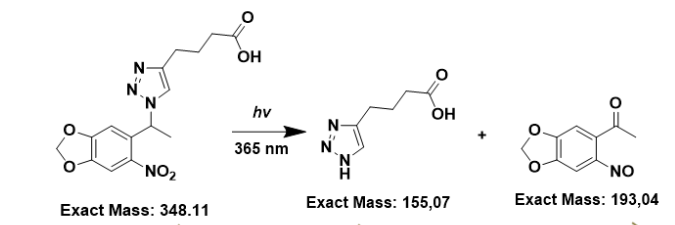

ESI-MS of partially photolyzed aliquot $(t=10 \mathrm{~min})$

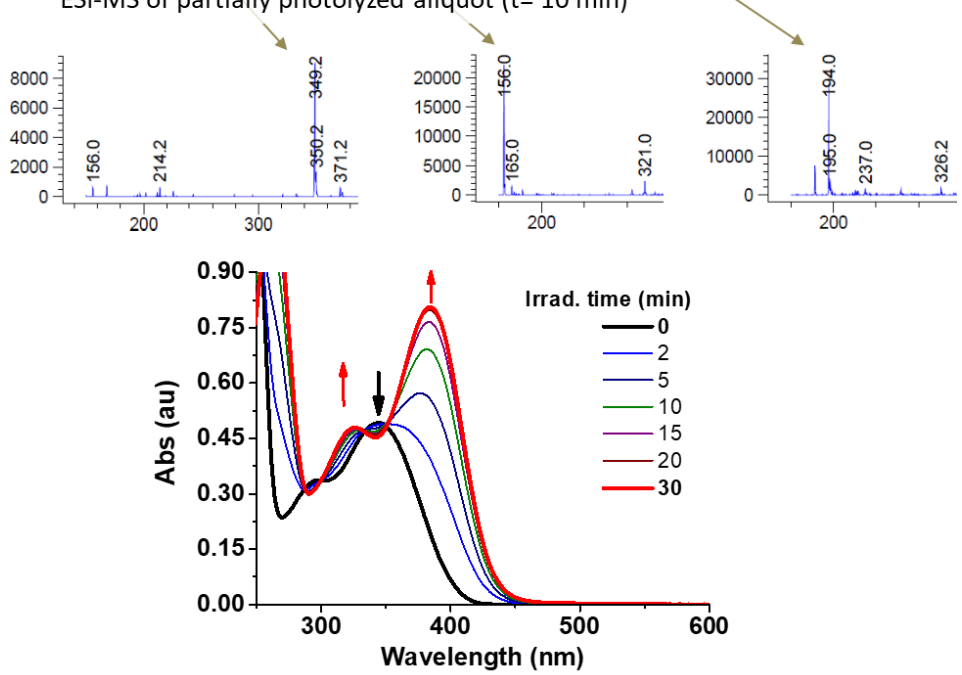

Figure 3. Photolysis studies in solution, followed by UV/Vis spectroscopy. A) $1 \mathrm{mM}$ solution of PEG-NBt-c in water at increasing exposure times $(\mathrm{t}=0-70 \mathrm{~min})$. B) $1 \mu \mathrm{M}$ solution of a small nitrobenzyl triazole model molecule in acetonitrile at increasing exposure times $(\mathrm{t}=0-30 \mathrm{~min})$. ESI-MS analysis of partially photolyzed solution $(\mathrm{t}=10 \mathrm{~min})$. The photolysis products triazole $(\mathrm{m} / \mathrm{z}=156.0$ for $\mathrm{M}+\mathrm{H})$ and nitroso-ketone $(\mathrm{m} / \mathrm{z}=194.0$ for $\mathrm{M}+\mathrm{H})$ as well as the signal for the 
original molecule were detected $(\mathrm{m} / \mathrm{z}=349.2$ for $\mathrm{M}+\mathrm{H})$. Irradiation conditions: $\lambda=365 \mathrm{~nm}, 1.2$ $\mathrm{mW} \mathrm{cm} \mathrm{cm}^{-2}$.

Preparation and photodegradation properties of PEG-NBt-c hydrogels

PEG-NBt-c hydrogels were obtained from 10-20 wt\% solutions of PEG-NBt-c (10 or $20 \mathrm{kDa})$ in $50 \mathrm{mM}$ HEPES buffer at $\mathrm{pH} 7.5$ in the presence of 9-18 $\mathrm{mM} \mathrm{NaIO}_{4}$ as oxidant. Under these conditions the catechol group is expected to oxidize and self-polymerize to form a crosslinked network..$^{41}$ The obtained hydrogels were transparent, homogeneous and brownish orange. Hydrogel disks were formed in cylindrical molds $(20-100 \mu \mathrm{L})$ or directly in rheometer plates $(40$ $\mu \mathrm{L})$ for studies of crosslinking kinetics.

The crosslinking kinetics of the hydrogel was followed in the rheometer in a time sweep experiment. For this purpose, a solution of $10 \mathrm{wt} \%$ PEG-NBt-c $(10 \mathrm{kDa})$ and $18 \mathrm{mM} \mathrm{NaIO} 4$ (catechol groups to oxidant molar ratio=2.2) was used. A representative rheological curve is shown in Figure 3A. The gradual increase of G' over time reflects the progress of the crosslinking reaction. $\mathrm{G}^{\prime}$ reached $10 \mathrm{kPa}$ after $2 \mathrm{~h}$ and $17 \mathrm{kPa}$ in $6 \mathrm{~h}$. Note that catecholmedicated crosslinking can be significantly accelerated, and the final G' of the hydrogel can be increased, at higher $\mathrm{pH}$ or oxidant concentration. ${ }^{7,42}$ PEG-NBt-c at concentrations between 5 and 20 wt \% polymer content mixed with $\mathrm{NaIO}_{4}$ at oxidant:catechol ratios $2.2: 1$ to $1.1: 1$ rendered crosslinked hydrogels in 2 to 80 min with G' values between 0.1 and $10 \mathrm{kPa}$ (Fig. 3 and S5A-B). For the rheological studies, formulations with slow crosslinking kinetics were used to capture the whole kinetic curve in the experiment. 
The photodegradation of the hydrogel was followed by rheology using a transparent lower plate that allowed direct illumination of the probe $\left(\lambda=365 \mathrm{~nm}, 10 \mathrm{~mW} \mathrm{~cm}{ }^{-2}\right)$ while measuring. A rapid decay in G' was observed when light was turned on (Figure 3A-D, pink regions), indicating softening of the hydrogel due to photocleavage of the nitrobenzyl triazole unit. G' dropped from 17 to $1.7 \mathrm{kPa}\left(90 \%\right.$ decrease) within $30 \mathrm{~min}$ of illumination $\left(18 \mathrm{~J} \mathrm{~cm}^{-2}\right)$ and to 0.17 $\mathrm{kPa}\left(99 \%\right.$ decrease) after $45 \mathrm{~min}$ of irradiation $\left(27 \mathrm{~J} \mathrm{~cm}^{-2}\right)$. After $57 \mathrm{~min}$ exposure $\left(34 \mathrm{~J} \mathrm{~cm}^{-2}\right)$, G' and G' curves crossed, indicating the gel-sol transition, which was confirmed by the brownish liquid appearance of the sample at the end of the experiment. To confirm that the photodegradation of PEG-NBt-c gels occurs only by photocleavage of the nitrobenzyl triazole, control experiments were conducted with PEG-dopamine. ${ }^{41}$ In this case, irradiation did not cause any change of G' (Fig. S5A).

PEG-NBt-c hydrogels with lower crosslinking degrees degraded at significantly lower exposure doses. $10 \mathrm{wt} \%$ PEG-NBt-c $(20 \mathrm{kDa})$ precursors at the same crosslinking conditions formed hydrogels with $\mathrm{G}^{\prime}=1 \mathrm{kPa}$ and showed a $90 \%$ decay in $\mathrm{G}^{\prime}$ after $25 \mathrm{~min}$ of exposure $\left(15 \mathrm{~J} \mathrm{~cm}^{-2}\right.$, Fig. 3C). Hydrogels from $5 \mathrm{wt} \%$ PEG-NBt-c $(20 \mathrm{kDa})$ and $9 \mathrm{mM}$ oxidant concentration showed a G' of $0.1 \mathrm{kPa}$ and phozolyzed after 4 min exposure (2.4 J cm${ }^{-2}$, Fig. S5B). For reference, typical exposure conditions used for photodegradation of PEG hydrogels applied to cell encapsulation (with similar molar mass and concentration, $\mathrm{G}^{\prime} \sim 1.5$ to $5 \mathrm{kPa}^{27,32,43}$ ) are $\lambda=365 \mathrm{~nm}, \mathrm{I}=5-20 \mathrm{~mW}$ $\mathrm{cm}^{-2}$ and time $=2-30 \mathrm{~min}$, corresponding to total exposure doses of $5-10 \mathrm{~J} \mathrm{~cm}^{-2} .25-26,32,44$ The exposure doses required for photodegradation of PEG-NBt-c gels are, therefore, within cytocompatible ranges.

We tested if the photodegradation of the hydrogel could be regulated by the exposure dose. A hydrogel with initial G' $17 \mathrm{kPa}$ was illuminated with sequential pulses of 3 minutes. A $25 \%$ drop 
of G' $25 \%$ was observed in the first illumination cycle, and a drop of $80 \%$ in the second (Figure 3B). Similarly, a gel with initial G' $\sim 1 \mathrm{kPa}$ softened by $25 \%$ and then by $50 \%$ after 2 -min irradiation pulses (Figure 3D). The photodegradation was also regulated by the intensity of the lamp. Using irradiance values of 10,5 or $1 \mathrm{mWcm}^{-2}$ a $50 \%$ drop in $\mathrm{G}^{\prime}$ was obtained in $1.7,4.8$ and 17 min respectively (Figure 3E).

Considering the photodegradation of the hydrogel to be a first-order kinetic process, the drop in G' with exposure time can be used to estimate the rate constant of the photodegradation reaction $\left(k_{o b s}\right) .{ }^{27}$ The results for the hydrogels in Figure 3E are presented in Table 1 . A $k_{o b s}=6.8 \times 10^{-3} \mathrm{~s}^{-1}$ was obtained for hydrogels with nitrobenzyl triazole linker. This photodegradation kinetic constant is of the same order of magnitude as reported for nitrobenzyl esters, which ranged from 2.6 to 3.3 $\mathrm{x} 10^{-3} \mathrm{~s}^{-1} \cdot{ }^{26,32}$ Since the photodegradation is considered a first-order process, the rates of degradation at a given wavelength are expected to collapse to a single point when normalized by light intensity. ${ }^{45}$ This was the case for our hydrogels. The derived kinetic parameter, defined as $k_{o b s} / \mathrm{I}_{0}\left(\mathrm{x} 10^{4}\right)=7.0 \mathrm{~cm}^{2} \mathrm{~s}^{-1} \mathrm{~mW}^{-1}$, can be taken as an indication of photocleavage kinetics independent from the applied light. The obtained value matches that of nitrobenzyl esters (3.3-5.8 $\left.\mathrm{cm}^{2} \mathrm{~s}^{-1} \mathrm{~mW}^{-1}\right){ }^{26-27}$ In contrast, the nitrophenyl ethyl amide, also used to confer photodegradability to hydrogels, ${ }^{40}$ showed a 24 -fold slower photodegradation rate constant (Fig. S5C and Table S1). This is in agreement with photolysis results in solution (Fig. S4). 
A. PEG-NBt-c (10 kDa, $10 \mathrm{wt} \%, 18 \mathrm{mM}$ ox.)

B.
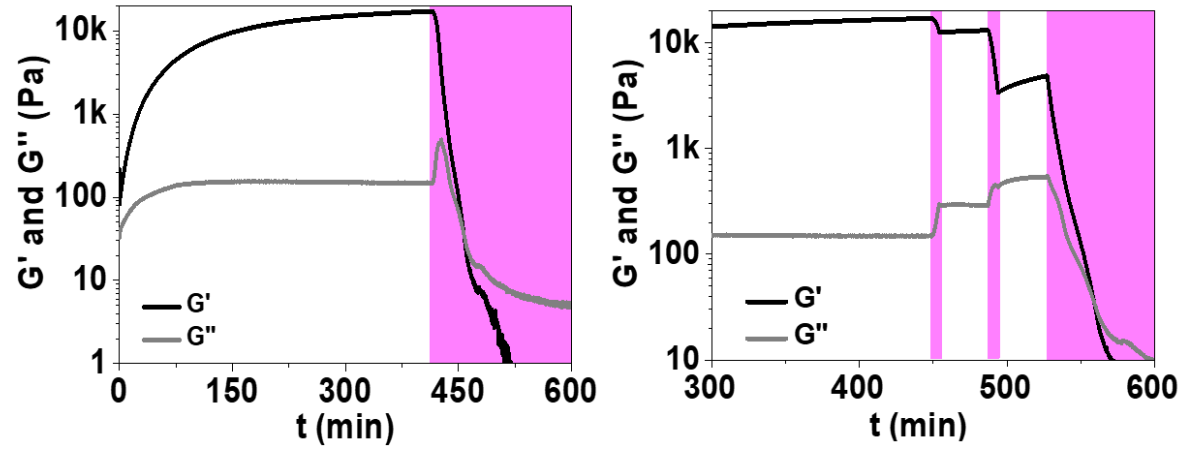

C.

PEG-NBt-c (20 kDa, 10 wt\%, 18 mM ox.)

D.
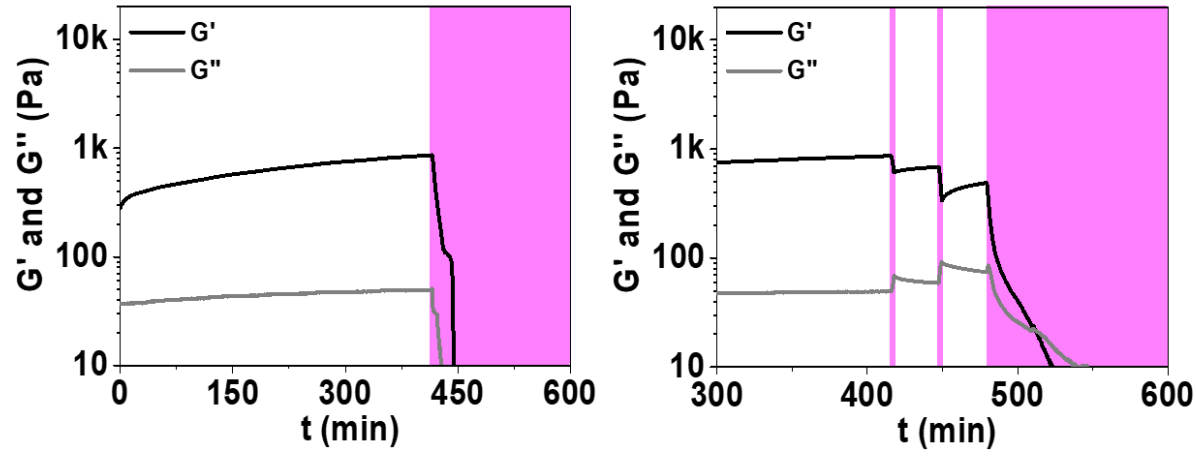

E.

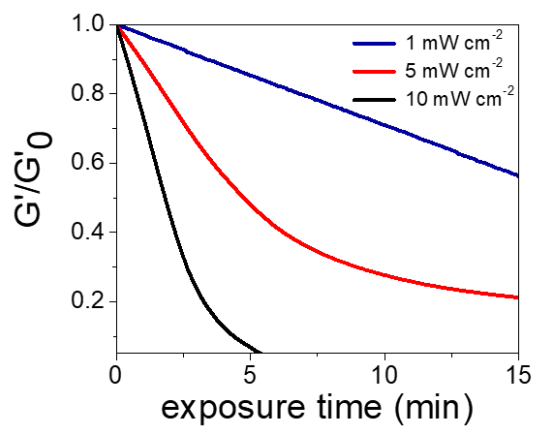

PEG-NBt-c (10 kDa, 10 wt\%, 9 mM ox.)
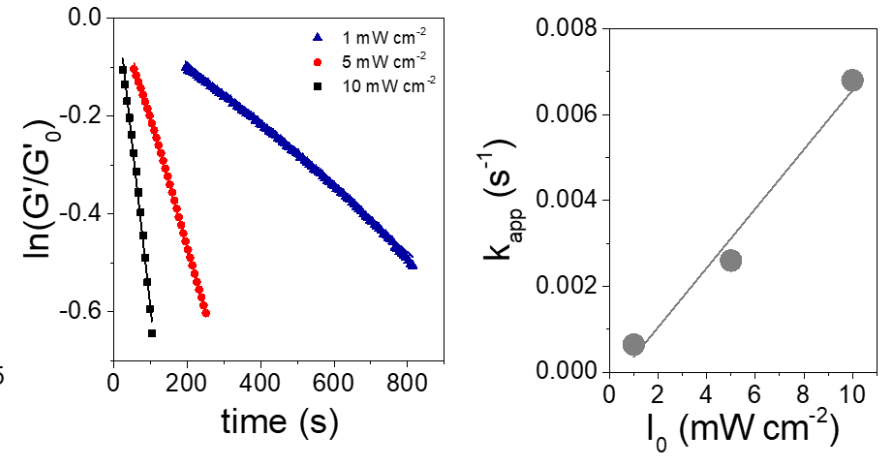

Figure 3. Rheology study of crosslinking and photodegradation kinetics of PEG-NBt-c hydrogels. A-D) Time sweep experiment during crosslinking and photodegradation steps $(\lambda=365 \mathrm{~nm}, 10 \mathrm{~mW}$ $\mathrm{cm}^{-2}$ ). Illumination periods are highlighted in pink. Composition of hydrogels: $10 \mathrm{kDa}(\mathrm{A}-\mathrm{B}, \mathrm{E})$ or $20 \mathrm{kDa}$ (C-D), $10 \mathrm{wt} \%$ polymer, $18 \mathrm{mM}$ (A-D) or $9 \mathrm{mM}$ (E) oxidant, $50 \mathrm{mM}$ HEPES buffer, $\mathrm{pH}$ 7.5. Catechol: $\mathrm{NaIO}_{4}$ molar ratio was 4.4 (in A-B) and 2.2 (in C-D). Light was continuous (A and C) or pulsed (pulse duration: $3 \mathrm{~min}$ in (B) and $2 \mathrm{~min}$ in (D)). E) Kinetic parameters for the photodegradation reaction extracted from photorheology data. Data correspond to hydrogels exposed with sources of irradiance 1,5 and $10 \mathrm{~mW} \mathrm{~cm}^{-2}$. 
Table 1. Kinetic parameters for the photodegradation reaction of nitrobenzyl triazole and nitrobenzyl ester units as obtained from photorheology measurements of the corresponding hydrogels.

\begin{tabular}{|l|l|l|}
\hline & $k_{o b s}\left[\mathrm{~s}^{-1}\right]$ & $k_{o b s} / \mathrm{I}_{0}\left(\mathrm{x} 10^{4}\right)\left[\mathrm{cm}^{2} \mathrm{~s}^{-1} \mathrm{~mW}^{-1}\right]$ \\
\hline PEG-NBt-e & \\
\hline
\end{tabular}

(a) Gel composition: 4-arm PEG, $10 \mathrm{kDa}, 10 \mathrm{wt} \%, 9 \mathrm{mM}$ ox., in $50 \mathrm{mM}$ HEPES buffer $\mathrm{pH} 7.5$, sample thickness $=250$ $\mu \mathrm{m}$. Irradiation conditions: $\lambda=365 \mathrm{~nm}, \mathrm{I}_{0}=10 \mathrm{~mW} \mathrm{~cm}^{-2}, \mathrm{~T}=25^{\circ} \mathrm{C}^{\text {(b) }}$ Calculated from the $\ln \left(G^{\prime} / G^{\prime} 0\right)$ vs. $t$ plot. (c) Calculated from $k_{o b s}$ vs. $I_{0}$ plot; $I_{0}=1,5$ and $10 \mathrm{~mW} \mathrm{~cm}^{-2}$. (d) $\lambda=365 \mathrm{~nm}, \mathrm{I}_{0}=10 \mathrm{~mW} \mathrm{~cm}{ }^{-2}$, obtained from Refs. ${ }^{26-27,} 32$

\section{Photopatterning of PEG-NBt-c hydrogels}

To demonstrate the spatial selectivity of the photodegradation process, PEG-NBt-c hydrogels were scanned with a laser scanning microscope (LSM, $\lambda=405 \mathrm{~nm}$ ). In order to visualize the illuminated sites the photoactivatable fluorophore 5-carboxymethoxy-2-nitrobenzyl ether (CMNB)-succinimidyl ester fluorescein was incorporated to the gel ${ }^{46}$ (Figure S6). A 200x200 $\mu \mathrm{m}^{2}$ square was scanned at the surface of the hydrogel at $2.6 \mathrm{~nJ}$ per voxel (Figure 4A).

Microscopy imaging showed a decrease of the bright field intensity in the illuminated region, which was attributed to the partial degradation and higher swelling of the hydrogel. A higher irradiation dose (211 nJ per voxel) rendered higher contrast in the bright field image, confirming a dose-dependent effect (Figure 4A). Figure 4B shows a cylindrical (diameter/height $300 \mu \mathrm{m} / 150$ $\mu \mathrm{m})$ volumes scanned at $15.1 \mathrm{~nJ}$ per voxel. For comparison, the experiment was performed on PEG-NBt-c hydrogels obtained from 10 and $20 \mathrm{kDa}$ precursors. Lower normalized bright field 
intensity values were observed for the $20 \mathrm{kDa}$ hydrogel (Fig. S6E and S7C), as expected from the lower crosslinking degree and, therefore, higher degradation at the same dose.

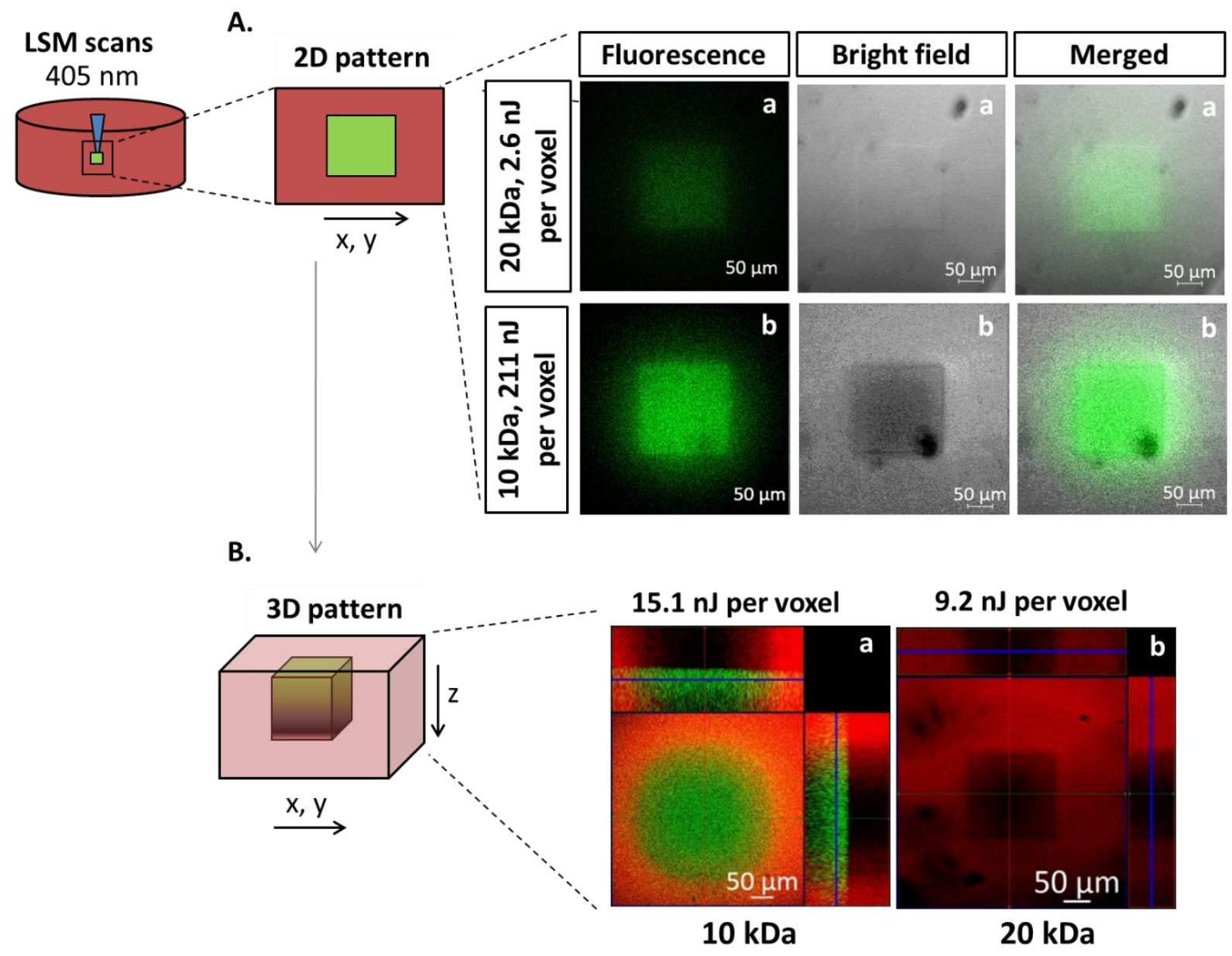

Figure 4. 2D and 3D patterning of photodegradable PEG-NBt-c hydrogels (gel composition: 10 or $20 \mathrm{kDa}, 10 \mathrm{wt} \%$ polymer, $18 \mathrm{mM}$ oxidant, $50 \mathrm{mM}$ HEPES buffer $\mathrm{pH} 7.5$ ). The hydrogel was labelled with $1 \mathrm{mM}$ CMNB-fluorescein. Images show z-stack images of the scanned region. Scale bars correspond to $50 \mu \mathrm{m}$. A) 2D square patterns $\left(200 \times 200 \mu \mathrm{m}^{2}\right)$ scanned at laser power $1 \%(2.6$ $\mathrm{nJ}$ per voxel) or $100 \%$ (211 $\mathrm{nJ}$ per voxel). The irradiated region appears fluorescent and is visible in the bright field. B) 3D patterns showing a cylinder (diameter/height $300 \mu \mathrm{m} / 150 \mu \mathrm{m}$ ) and a rectangular prism $\left(200 \times 200 \times 100 \mu \mathrm{m}^{3}\right)$ scanned at different laser power: $15 \%(15.1 \mathrm{~nJ}$ per voxel) and $8 \%$ power $(9.2 \mathrm{~nJ}$ per voxel) (conditions: scan speed setting $=1($ P.Dwell $=131.88 \mu \mathrm{sec})$, passing number $=1)$. 
To further confirm photodegradation of the network at the irradiated areas we encapsulated fluorescently labelled $30 \mu \mathrm{m}$ polystyrene particles into PEG-NBt-c hydrogels and measured their position before and after exposure by LSM. Embedded particles in areas illuminated at $11 \mathrm{~nJ}$ per voxel moved from their original location, and particles were released at $44 \mathrm{~nJ}$ per voxel (Fig. S8A). In contrast, particles embedded in the control PEG-NDop hydrogel required $1688 \mathrm{~nJ}$ per voxel to be released.

\section{Cytocompatibility of PEG-NBt-c hydrogels}

The cytocompatibility of PEG-NBt-c hydrogels was tested in vitro. L929 fibroblasts cultured on a plastic culture plate were contacted with PEG-NBt-c gels and cultured for $1 \mathrm{~d}$. Live/dead assay indicated $97 \%$ cell viability (Fig. S10A). Viability was further corroborated in a 3D cell encapsulation experiment. Fibroblasts were encapsulated in PEG-NBt-c gels (final gel composition was: $10 \mathrm{kDa}, 10 \mathrm{wt} \%$ PEG polymers, $18 \mathrm{mM}$ oxidant, $1 \mathrm{mM}$ cyclo(RGDfC) peptide, $50 \mathrm{mM}$ HEPES buffer, $\mathrm{pH}$ 7.5; see Supporting Information for details on the preparation protocol). Oxidant concentrations of 10-30 $\mathrm{mM}$ have been previously used for cell encapsulation and in vivo tissue adhesion with catechol-PEGs. ${ }^{6,9-10,14,47}$ The gels were let cure for 30 min at 37 ${ }^{\circ} \mathrm{C}$ and cell culture medium was replaced. The cell culture medium was exchanged every day. The viability of the cells in the 3D culture was tested after $3 \mathrm{~d}$ of culture. Viability ratios of $\sim 91 \%$ (Figure S9B) were observed. These data corroborate the cytocompatibility of PEG-NBt-c hydrogels as materials for cell encapsulation. 
Photodegradation of PEG-NBt-c matrices in $2 D$ cell cultures

We next studied if photodegradation of PEG-NBt-c gels in the presence of cells would have a negative effect on cellular function. Hydrogel films $(10 \mathrm{kDa}, 10 \mathrm{wt} \%, 18 \mathrm{mM} \mathrm{NaIO} 4)$ were prepared on tissue culture plates and coated with collagen I as cell adhesive protein before seeding L929 fibroblast. Fibroblasts attached to the gels within $4 \mathrm{~h}$ (data not shown). After $4 \mathrm{~d}$ of culture, cells covered the gel surface and spread (Figure 5A), and viability ratios of $99 \%$ were obtained (Figure 5C). The culture surface was exposed to light $\left(\lambda=365 \mathrm{~nm}, 2.6 \mathrm{~mW} \mathrm{~cm}{ }^{-2}\right)$ for increasing times between 3 and 7 min (i.e. irradiation doses between 0.5 and $1.1 \mathrm{~J} \mathrm{~cm}^{-2}$ ). According to our photorheology data in Fig. 3B, this dose is expected to degrade $<25 \%$ of the gel. With increasing exposure time we observed that some cells detached from the hydrogel surface. In order to quantify this observation, the remained attached cells were removed from the hydrogel by trypsinization ${ }^{48}$ and counted. Cell number decreased with increasing illumination dose down to $57 \%$ after $7 \mathrm{~min}$ irradiation (exposure dose $=1.1 \mathrm{~J} \mathrm{~cm}^{-2}$ ) (Figure $\left.\mathrm{S} 11 \mathrm{G}\right)$. These results demonstrate that the lightinduced degradation of the PEG-NBt-c gel surface leads to detachment of the originally adhered cells in a dose-dependent manner. Attached cells showed viability ratios of $>97 \%$ in the life/dead assay after exposure (Fig. 5C and Fig. S11E). The viability ratio was confirmed by a LDH assay (see Fig. S11F). Detached cells from the hydrogels after exposure were collected, cultured for 12 $\mathrm{h}$ on tissue culture plates, and cell density and viability were analyzed. Cell number increased with increasing irradiation dose (Fig. S11G) and cell viability remained $>90 \%$ for all cases (Figure 5C). These results indicate that the exposure conditions and the photolysis products did not lead to appreciable photodamage of the cells (see also Fig. S10). 


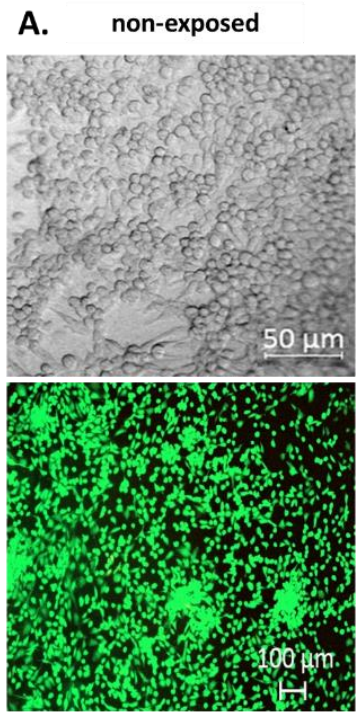

B. exposed $\left(1.1 \mathrm{~J} \mathrm{~cm}^{-2}\right)$

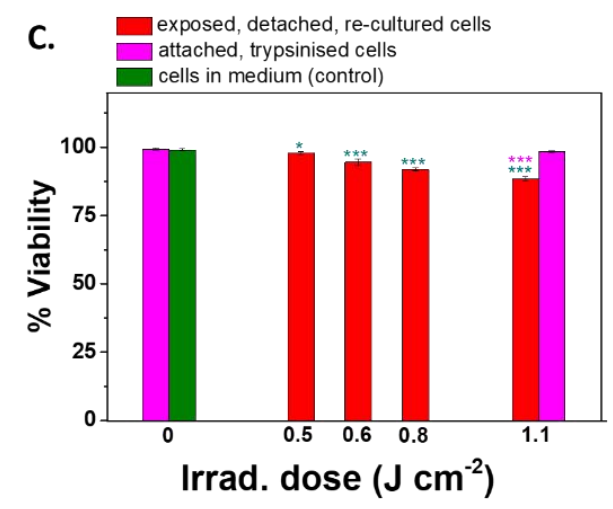

Figure 5. L929 fibroblasts culture on the PEG-NBt-c hydrogels (10 kDa, $10 \mathrm{wt} \%, 18 \mathrm{mM} \mathrm{NaIO}_{4}$ in $50 \mathrm{mM}$ HEPES buffer, $\mathrm{pH} 7.5$, coated with collagen I). (A) Bright field and fluorescence microscopy images of fibroblasts cultured on the hydrogel for $4 \mathrm{~d}$ and tested with life/day assay. (B) Remained cells on the surface of the hydrogels after exposure at $1.1 \mathrm{~J} \mathrm{~cm}^{-2}(\lambda=365 \mathrm{~nm}, 2.6$ $\mathrm{mW} \mathrm{cm}{ }^{-2}$ ). (C) Detached cells after exposure were seeded on tissue culture plate for $12 \mathrm{~h}$ and analyzed for viability. Scale bars: $50 \mu \mathrm{m}$ for bright field, $100 \mu \mathrm{m}$ for fluorescence channel. Statistical significance analysis was performed by ANOVA followed by post-hoc Tukey test (mean \pm SD; $* \mathrm{p}<0.05, * * * \mathrm{p}<0.001$ used for statistical significance).

Photodegradable $3 D$ cell cultures in PEG-NBt-c hydrogels

Spheroids of L929 fibroblasts ${ }^{49}$ were embedded in PEG-NBt-c hydrogels functionalized with the cell adhesive peptide cyclo(RGDfC). Final gel composition was $10 \mathrm{kDa}, 10 \mathrm{wt} \%$ polymer, 18 
$\mathrm{mM} \mathrm{NaIO} 4,1 \mathrm{mM}$ cyclo(RGDfC). Embedded spheroids remained confined in the hydrogel and viable ( $>90 \%$ after $3 \mathrm{~d}$ culture, Figure S9C). The stability of the hydrogel structure and the high crosslinking degree do not allow cells to invade the matrix and proliferate outside of the spheroid. We tested if photodegradation of the hydrogel around the spheroid could trigger migration of the cells from the spheroids into the surrounding matrix. Spheroids were cultured for $7 \mathrm{~h}$ and a volume around them was illuminated (volume $=100 \times 100 \times 15 \mu \mathrm{m}^{3}$, dose $=18.4 \mathrm{~nJ}$ per voxel). Within the following $2 \mathrm{~d}$, fibroblasts migrated from the spheroid into the illuminated region. This became more evident after $5 \mathrm{~d}$ of culture, as revealed by the larger migration distances covered by the cells (ca $70 \mu \mathrm{m}$, Fig. 6B). Cells did not invade the non-irradiated areas. At longer culture times ( 9 d) cells from two spheroids separated by $100 \mu \mathrm{m}$ were connected via an illuminated bridge between them (Figure S12e). These results demonstrate that controlled light exposure of PEG-NBt-c hydrogels allows regulated degradation and control of cell migration inside the hydrogel. 
A.

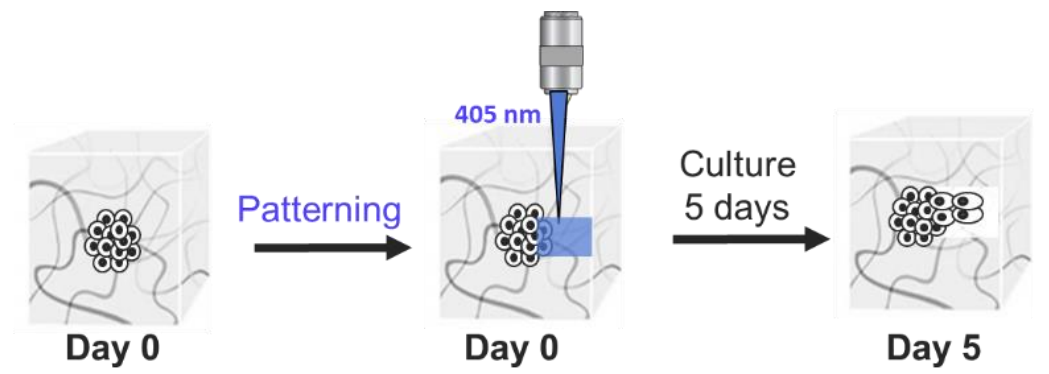

B.

Day of spheroid culture after irradiation

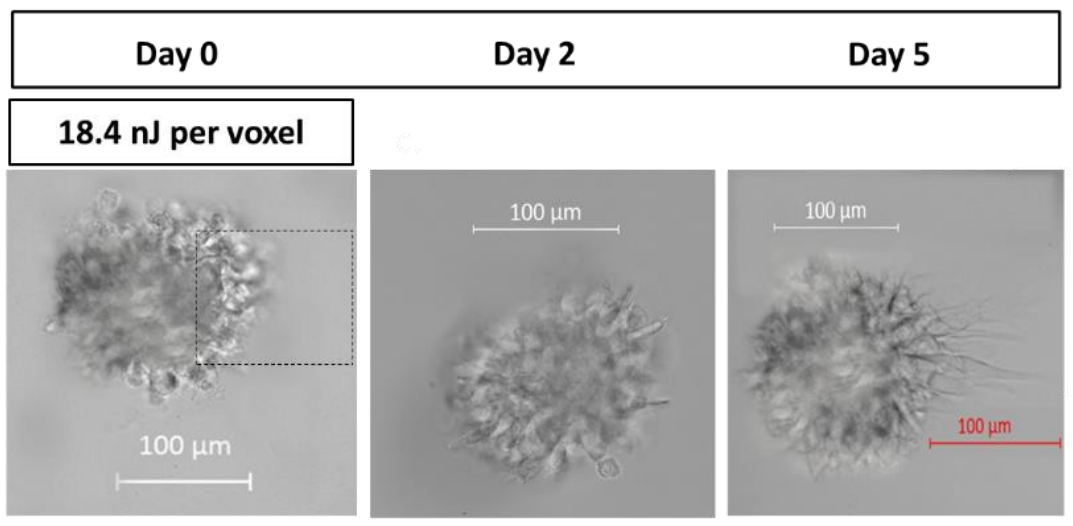

Figure 6. 3D cell culture of fibroblast spheroids in PEG-NBt-c hydrogels (gel composition: 10 $\mathrm{kDa}, 10 \mathrm{wt} \%$ polymer, $18 \mathrm{mM}$ oxidant, $1 \mathrm{mM}$ cyclo(RGDfC) peptide) and light exposed (singlephoton LSM irradiation, $\lambda=405 \mathrm{~nm}$; laser power $8 \%$ : $0.14 \mathrm{~mW}$ and dose $=18.4 \mathrm{~nJ}$ per voxel). A) Schematics of the light-mediated control of cell invasion on the matrices. B) L929 fibroblast spheroids were encapsulated in PEG-NBt-c hydrogels, cultured for $7 \mathrm{~h}$, then a volume at the border of spheroid (indicated by dashed rectangles) was irradiated. After exposure, cell migration out of the spheroid was analyzed over $5 \mathrm{~d}$ of culture. Scale bars: $100 \mu \mathrm{m}$.

\section{Adhesion of PEG-NBt-c hydrogels to tissue and light-mediated debonding}

The adhesion of PEG-NBt-c hydrogels to wet tissues and the possibility to trigger debonding by light exposure were tested in adhesion experiments using skin (from chicken) as substrate. ${ }^{6-7,9,14,}$ ${ }^{50-51}$ A final composition of 10 wt\% PEG-NBt-c, $18 \mathrm{mM} \mathrm{NaIO}_{4}, 50 \mathrm{mM}$ HEPES buffer pH 7.5 was used. In order to facilitate imaging of the transparent hydrogel, fluorescent beads were also added to the precursor mixture. The mixture was applied on the skin surface and cured for $1 \mathrm{~h}$ in humid atmosphere at $37^{\circ} \mathrm{C}$. These conditions should simulate the application scenario of medical tissue 
adhesives. The hydrogel attached to the skin tissue and remained bonded after $30 \mathrm{~min}$ of vigorous shaking of the substrate underwater (Fig. 7A and Fig. S14A-B). Figure 7C shows the adhesive with the embedded fluorescent beads atop the skin. ESEM imaging of the cross-section of the tissue confirmed the conformal contact between the tissue surface and the adhesive hydrogel (Figure S16). These results indicate that a strong interface is built, presumably involving covalent bonds between catechol groups of the adhesive and the tissue. ${ }^{14}$

The adhesive bond was exposed to $365 \mathrm{~nm}$ light $\left(70 \mathrm{~mW} \mathrm{~cm}{ }^{-2}\right.$ for $\left.6 \mathrm{~min}, 25 \mathrm{~J} \mathrm{~cm}^{-2}\right)$ and soaked in water. Debonding of the PEG-NBt-c hydrogel from the skin tissue was observed macroscopically by naked eye (Fig. 7B and S17) and microscopically by fluorescence imaging of the outer tissue layer of the illuminated construct (Fig. 7D). These results confirm that PEG-NBt-c hydrogels can attach to tissue and detach on-demand upon exposure to light. The sum of properties demonstrated for this material, i.e. in situ gelation, cytocompatibility, and reversible tissue adhesiveness, are interesting for the application fields of wound management and tissue repair. 
Macroscopic view

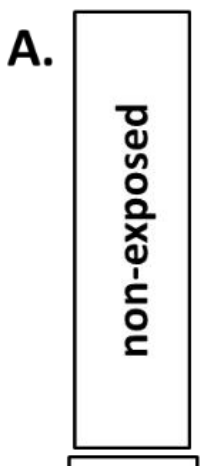

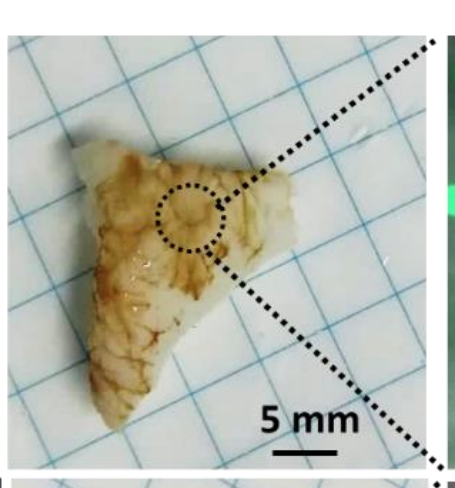

Fluorescence imaging, top view

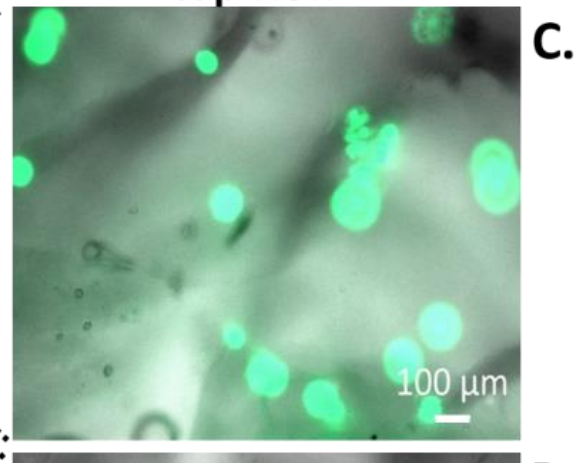

B.

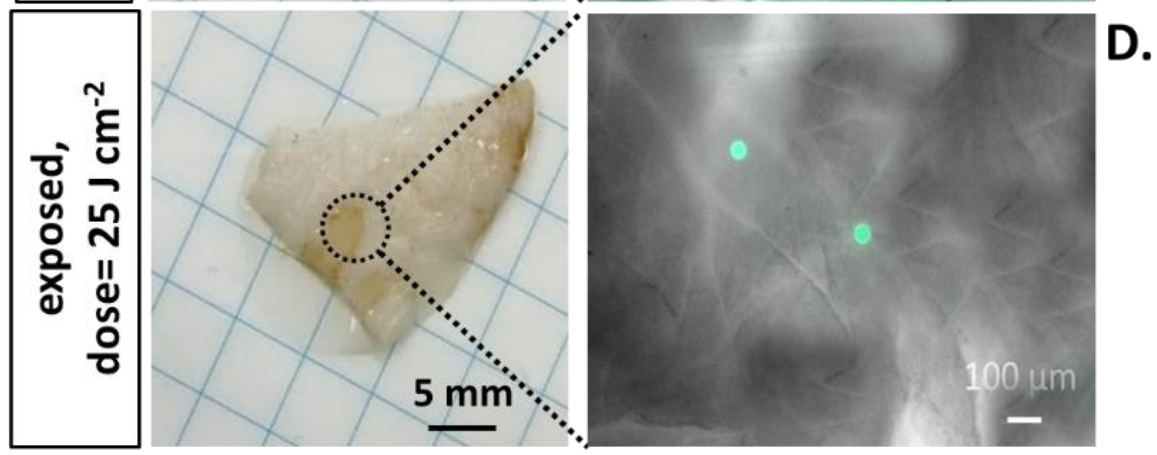

Figure 7. Macroscopic and microscopic visualization of the tissue adhesiveness of PEG-NBt-c hydrogel tested on chicken skin, before (A, C) and after (B, D) light exposure. A-B) Macroscopic view of the bonded tissue. C-D) Fluorescence imaging of the outer tissue layer; where embedded fluorescent PSPs in the adhesive hydrogel facilitate the visualization of the presence of hydrogel material bond to the tissue. Final gel composition: $10 \mathrm{kDa}, 10 \mathrm{wt} \%$ PEG-NBt-c, $18 \mathrm{mM}$ oxidant containing fluorescent PSPs, $50 \mathrm{mM}$ HEPES buffer, $\mathrm{pH}$ 7.5. Irradiation conditions: $\lambda=365 \mathrm{~nm}$, irradiance $=70 \mathrm{~mW} \mathrm{~cm}{ }^{-2}$, for exposure time $=6 \min \left(\right.$ dose $\left.=25 \mathrm{~J} \mathrm{~cm}^{-2}\right)$. Scale bars $=5 \mathrm{~mm}$ (left) and $100 \mu \mathrm{m}$ (right).

\section{Conclusions}

A bioinspired hydrogel is presented that can polymerize under mild conditions and depolymerize by light exposure at cell compatible doses. It is based on a starPEG-macromer containing intercalated photocleavable nitrobenzyl triazole units and terminal catechol groups. Oxidative crosslinking of the catechol groups allows gelation in the presence of cells. The precursor mixture can be adjusted to achieve hydrogels with mechanical properties within relevant 
physiological ranges. The efficiency of the photodegradation reaction is similar to the efficiency of nitrobenzyl ester analogs that are typically used for dynamic cell culture. However, the hydrolytic stability of the nitrobenzyl triazole linkage is higher than the nitrobenzyl ester, making the former system more suitable for long term cell cultures.

Previous work has reported hydrogels that combine two key properties: tissue adhesion and cytocompatibility ${ }^{14}$ tissue adhesion and photodegradability,${ }^{34}$ cytocompatibility and photodegradability for controlled release. ${ }^{26}$ To our knowledge, the PEG-NBt-c system presented here is the first one that presents tissue adhesion, photodegradability and suitability for cell culture and controlled cell release under cytocompatible conditions. These properties are relevant in biomaterials for cell therapies and advanced, bioactive wound dressings. ${ }^{35-36}$

The modular character of the hydrogel precursor enables variations of the molecular design to further tune hydrogel properties. For example, the PEG polymer backbone can be replaced by other biocompatible backbones. The catechol end group can be exchanged by substituted catechols to accelerate crosslinking kinetics under mild oxidative conditions (from min-h to smin) while not altering the adhesion strength ${ }^{41}$ of the adhesive. This is relevant on the application site to provide comfortable time frame for the handling of the hydrogel solution before administration. ${ }^{52}$ 


\section{ASSOCIATED CONTENT}

Supporting Information. Experimental section containing details on the synthesis of hydrogel precursors and their photolysis and hydrolytic stability studies; additional rheological, microscopy and biological studies of hydrogels; and supplementary figures.

\section{AUTHOR INFORMATION}

\section{Corresponding Authors}

* Dr. Julieta I. Paez: julieta.paez@,1eibniz-inm.de, * Prof. Dr. Aránzazu del Campo: aranzazu.delcampo@,leibniz-inm.de.

\section{Author Contributions}

J.I.P. and A.d.C. conceived, designed and supervised the project. M.V. performed most experimental work. J.I.P. contributed with synthetic work. A.d.C. acquired funding. All authors participated in data analysis. The manuscript was written through contributions of all authors. All authors have given approval to the final version of the manuscript.

\section{Funding Sources}

This project was funded by the European Union within the Marie Sklodowska-Curie Innovative Training School (BioSmartTrainee, Project No. 642861) and the research and innovation programme under the FET PROACTIVE grant agreement No. 731957 (Mechano-Control).

\section{ACKNOWLEDGMENTS}

The authors thank Claudia Fink-Straube and Ha Rimbach-Nguyen for mass spectrometry measurements, Markus Koch for help with ESEM measurements, Emmanuel Terriac, Thomas Ruckelshausen and Karin Kiefer for help with microscopy. They also thank Stefan Brück, 
Aleeza Farrukh, Yijun Zheng, Samuel Pearson and M.K. Wlodarczyk-Biegun for helpful and stimulating discussions.

References

1. Patenaude, M.; Smeets, N. M. B.; Hoare, T., Designing Injectable, Covalently CrossLinked Hydrogels for Biomedical Applications. Macromol. Rapid Commun. 2014, 35 (6), 598617.

2. Ding, X.; Wang, Y., Weak bond-based injectable and stimuli responsive hydrogels for biomedical applications. J. Mater. Chem. B 2017, 5 (5), 887-906.

3. Caló, E.; Khutoryanskiy, V. V., Biomedical applications of hydrogels: A review of patents and commercial products. Eur. Polym. J. 2015, 65, 252-267.

4. Ghobril, C.; Grinstaff, M. W., The chemistry and engineering of polymeric hydrogel adhesives for wound closure: a tutorial. Chem. Soc. Rev. 2015, 44 (7), 1820-1835.

5. Bouten, P. J. M.; Zonjee, M.; Bender, J.; Yauw, S. T. K.; van Goor, H.; van Hest, J. C. M.; Hoogenboom, R., The chemistry of tissue adhesive materials. Prog. Polym. Sci. 2014, 39 (7), 1375-1405.

6. Liu, Y.; Meng, H.; Konst, S.; Sarmiento, R.; Rajachar, R.; Lee, B. P., Injectable dopaminemodified poly (ethylene glycol) nanocomposite hydrogel with enhanced adhesive property and bioactivity. ACS Appl. Mater. Interfaces 2014, 6 (19), 16982-16992. 
7. Feng, J.; Ton, X.-A.; Zhao, S.; Paez, J. I.; del Campo, A., Mechanically Reinforced Catechol-Containing Hydrogels with Improved Tissue Gluing Performance. Biomimetics 2017, 2 (4), 23.

8. Lu, D.; Wang, H.; Li, T. e.; Li, Y.; Dou, F.; Sun, S.; Guo, H.; Liao, S.; Yang, Z.; Wei, Q.; Lei, Z., Mussel-Inspired Thermoresponsive Polypeptide-Pluronic Copolymers for Versatile Surgical Adhesives and Hemostasis. ACS Appl. Mater. Interfaces 2017, 9 (20), 16756-16766.

9. Bilic, G.; Brubaker, C.; Messersmith, P. B.; Mallik, A. S.; Quinn, T. M.; Haller, C.; Done, E.; Gucciardo, L.; Zeisberger, S. M.; Zimmermann, R., Injectable candidate sealants for fetal membrane repair: bonding and toxicity in vitro. Am. J. Obstet. Gynecol. 2010, 202 (1), 85. e1-85. e9.

10. Kastrup, C. J.; Nahrendorf, M.; Figueiredo, J. L.; Lee, H.; Kambhampati, S.; Lee, T.; Cho, S.-W.; Gorbatov, R.; Iwamoto, Y.; Dang, T. T.; Dutta, P.; Yeon, J. H.; Cheng, H.; Pritchard, C. D.; Vegas, A. J.; Siegel, C. D.; MacDougall, S.; Okonkwo, M.; Thai, A.; Stone, J. R.; Coury, A. J.; Weissleder, R.; Langer, R.; Anderson, D. G., Painting blood vessels and atherosclerotic plaques with an adhesive drug depot. Proc. Natl. Acad. Sci. U.S.A. 2012, 109 (52), 21444-21449.

11. Ryu, J. H.; Lee, Y.; Kong, W. H.; Kim, T. G.; Park, T. G.; Lee, H., Catechol-Functionalized Chitosan/Pluronic Hydrogels for Tissue Adhesives and Hemostatic Materials. Biomacromolecules 2011, 12 (7), 2653-2659.

12. Puertas-Bartolomé, M.; Vázquez-Lasa, B.; San Román, J., Bioactive and Bioadhesive Catechol Conjugated Polymers for Tissue Regeneration. Polymers 2018, 10 (7), 768. 
13. Chen, T.; Chen, Y.; Rehman, H. U.; Chen, Z.; Yang, Z.; Wang, M.; Li, H.; Liu, H., Ultratough, Self-Healing, and Tissue-Adhesive Hydrogel for Wound Dressing. ACS Appl. Mater. Interfaces 2018, 10 (39), 33523-33531.

14. Brubaker, C. E.; Kissler, H.; Wang, L.-J.; Kaufman, D. B.; Messersmith, P. B., Biological performance of mussel-inspired adhesive in extrahepatic islet transplantation. Biomaterials 2010, $31(3), 420-427$.

15. Rahimnejad, M.; Zhong, W., Mussel-inspired hydrogel tissue adhesives for wound closure. RSC Adv. 2017, 7 (75), 47380-47396.

16. Pandey, N.; Soto-Garcia, L. F.; Liao, J.; Philippe, Z.; Nguyen, K. T.; Hong, Y., Musselinspired bioadhesives in healthcare: design parameters, current trends, and future perspectives. Biomater. Sci. 2020, 8 (5), 1240-1255.

17. Ignacio, C.; Barcellos, L.; Ferreira, M. D.; Moura, S. A. L.; Soares, I. A.; Oréfice, R. L., In vivo tests of a novel wound dressing based on biomaterials with tissue adhesion controlled through external stimuli. J. Mater. Sci.: Mater. Med. 2011, 22 (5), 1357-1364.

18. Chen, F.; Zhu, Y., Chitosan enclosed mesoporous silica nanoparticles as drug nanocarriers: Sensitive response to the narrow pH range. Micropor. Mesopor. Mat. 2012, 150, 83-89.

19. Konieczynska, M. D.; Villa-Camacho, J. C.; Ghobril, C.; Perez-Viloria, M.; Tevis, K. M.; Blessing, W. A.; Nazarian, A.; Rodriguez, E. K.; Grinstaff, M. W., On-Demand Dissolution of a Dendritic Hydrogel-based Dressing for Second-Degree Burn Wounds through Thiol-Thioester Exchange Reaction. Angew. Chem. Int. Ed. 2016, 55 (34), 9984-9987. 
20. Xu, Q.; Guo, L.; A, S.; Gao, Y.; Zhou, D.; Greiser, U.; Creagh-Flynn, J.; Zhang, H.; Dong, Y.; Cutlar, L.; Wang, F.; Liu, W.; Wang, W.; Wang, W., Injectable hyperbranched poly( $\beta$-amino ester) hydrogels with on-demand degradation profiles to match wound healing processes. Chem. Sci. 2018, 9 (8), 2179-2187.

21. Sadat Ebrahimi, M. M.; Schönherr, H., Enzyme-Sensing Chitosan Hydrogels. Langmuir 2014, 30 (26), 7842-7850.

22. Wang, L.; Neumann, M.; Fu, T.; Li, W.; Cheng, X.; Su, B.-L., Porous and responsive hydrogels for cell therapy. Curr. Opin. Colloid Interface Sci. 2018, 38, 135-157.

23. Ruskowitz, E. R.; Deforest, C. A., Photoresponsive biomaterials for targeted drug delivery and 4D cell culture. Nat. Rev. Mater. 2018, 3.

24. Truong, V. X.; Tsang, K. M.; Simon, G. P.; Boyd, R. L.; Evans, R. A.; Thissen, H.; Forsythe, J. S., Photodegradable Gelatin-Based Hydrogels Prepared by Bioorthogonal Click Chemistry for Cell Encapsulation and Release. Biomacromolecules 2015, 16 (7), 2246-2253.

25. Kloxin, A. M.; Kasko, A. M.; Salinas, C. N.; Anseth, K. S., Photodegradable Hydrogels for Dynamic Tuning of Physical and Chemical Properties. Science 2009, 324 (5923), 59-63.

26. Griffin, D. R.; Kasko, A. M., Photodegradable Macromers and Hydrogels for Live Cell Encapsulation and Release. J. Am. Chem. Soc. 2012, 134 (31), 13103-13107.

27. LeValley, P. J.; Neelarapu, R.; Sutherland, B. P.; Dasgupta, S.; Kloxin, C. J.; Kloxin, A. M., Photolabile Linkers: Exploiting Labile Bond Chemistry to Control Mode and Rate of Hydrogel Degradation and Protein Release. J. Am. Chem. Soc. 2020, 142 (10), 4671-4679. 
28. Raman, R.; Hua, T.; Gwynne, D.; Collins, J.; Tamang, S.; Zhou, J.; Esfandiary, T.; Soares, V.; Pajovic, S.; Hayward, A.; Langer, R.; Traverso, G., Light-degradable hydrogels as dynamic triggers for gastrointestinal applications. Sci. $A d v$. 2020, 6 (3), eaay0065.

29. Huynh, C. T.; Nguyen, M. K.; Tonga, G. Y.; Longé, L.; Rotello, V. M.; Alsberg, E., Photocleavable Hydrogels for Light-Triggered siRNA Release. Adv. Healthcare Mater. 2016, 5 (3), 305-310.

30. Pang, Q.; Lou, D.; Li, S.; Wang, G.; Qiao, B.; Dong, S.; Ma, L.; Gao, C.; Wu, Z., Smart Flexible Electronics-Integrated Wound Dressing for Real-Time Monitoring and On-Demand Treatment of Infected Wounds. Adv. Sci. 2020, 7 (6), 1902673.

31. van der Vlies, A. J.; Barua, N.; Nieves-Otero, P. A.; Platt, T. G.; Hansen, R. R., On Demand Release and Retrieval of Bacteria from Microwell Arrays Using Photodegradable Hydrogel Membranes. ACS Appl. Bio Mater. 2019, 2 (1), 266-276.

32. DeForest, C. A.; Anseth, K. S., Cytocompatible click-based hydrogels with dynamically tunable properties through orthogonal photoconjugation and photocleavage reactions. Nat. Chem. 2011, 3 (12), 925-931.

33. Website: https://www.lumina.se; accessed on April 2020

34. Wu, H.; Qin, Z.; Yu, X.; Li, J.; Lv, H.; Yang, X., On-demand removable hydrogels based on photolabile cross-linkings as wound dressing materials. J. Mater. Chem. B 2019, 7 (37), 56695676.

35. Antonio, F.; Petya, P.; Tzanko, T., Hydrogel Dressings for Advanced Wound Management. Curr. Med. Chem. 2018, 25 (41), 5782-5797. 
36. Op 't Veld, R. C.; Walboomers, X. F.; Jansen, J. A.; Wagener, F. A. D. T. G., Design Considerations for Hydrogel Wound Dressings: Strategic and Molecular Advances. Tissue Eng. Part B Rev. 2020, in press.

37. Ruskowitz, E. R.; DeForest, C. A., Photoresponsive biomaterials for targeted drug delivery and 4D cell culture. Nature Reviews Materials 2018, 3 (2), 17087.

38. Qvortrup, K.; Nielsen, T. E., A photolabile linker for the solid-phase synthesis of 4substituted NH-1,2,3-triazoles. ChemComm 2011, 47 (11), 3278-3280.

39. Hansen, M. J.; Velema, W. A.; Lerch, M. M.; Szymanski, W.; Feringa, B. L., Wavelengthselective cleavage of photoprotecting groups: strategies and applications in dynamic systems. Chem. Soc. Rev. 2015, 44 (11), 3358-3377.

40. Shafiq, Z.; Cui, J.; Pastor-Pérez, L.; San Miguel, V.; Gropeanu, R. A.; Serrano, C.; del Campo, A., Bioinspired Underwater Bonding and Debonding on Demand. Angew. Chem. Int. Ed. 2012, 51 (18), 4332-4335.

41. Paez, J. I.; Ustahüseyin, O.; Serrano, C.; Ton, X.-A.; Shafiq, Z.; Auernhammer, G. K.; d'Ischia, M.; del Campo, A., Gauging and Tuning Cross-Linking Kinetics of Catechol-PEG Adhesives via Catecholamine Functionalization. Biomacromolecules 2015, 16 (12), 3811-3818.

42. Cencer, M.; Liu, Y.; Winter, A.; Murley, M.; Meng, H.; Lee, B. P., Effect of pH on the Rate of Curing and Bioadhesive Properties of Dopamine Functionalized Poly(ethylene glycol) Hydrogels. Biomacromolecules 2014, 15 (8), 2861-2869.

43. Truong, V. X.; Li, F.; Forsythe, J. S., Photolabile Hydrogels Responsive to Broad Spectrum Visible Light for Selective Cell Release. ACS Appl. Mater. Interfaces 2017, 9 (38), 32441-32445. 
44. Wong, D. Y.; Ranganath, T.; Kasko, A. M., Low-Dose, Long-Wave UV Light Does Not Affect Gene Expression of Human Mesenchymal Stem Cells. PLOS ONE 2015, 10 (9), e0139307.

45. Azagarsamy, M. A.; McKinnon, D. D.; Alge, D. L.; Anseth, K. S., Coumarin-Based Photodegradable Hydrogel: Design, Synthesis, Gelation, and Degradation Kinetics. ACS Macro Lett. 2014, 3 (6), 515-519.

46. Farrukh, A.; Paez, J. I.; del Campo, A., 4D Biomaterials for Light-Guided Angiogenesis. Adv. Funct. Mater. 2019, 29 (6), 1807734.

47. Hong, S.; Yang, K.; Kang, B.; Lee, C.; Song, I. T.; Byun, E.; Park, K. I.; Cho, S.-W.; Lee, H., Hyaluronic Acid Catechol: A Biopolymer Exhibiting a pH-Dependent Adhesive or Cohesive Property for Human Neural Stem Cell Engineering. Adv. Funct. Mater. 2013, 23 (14), 1774-1780.

48. https://www.sigmaaldrich.com/technical-documents/articles/biology/cell-dissociationwith-trypsin.html; access date: April 2020.

49. Zheng, Y.; Han, M. K. L.; Jiang, Q.; Li, B.; Feng, J.; del Campo, A., 4D hydrogel for dynamic cell culture with orthogonal, wavelength-dependent mechanical and biochemical cues. Mater. Horiz. $\mathbf{2 0 2 0 .}$

50. Kivelio, A.; DeKoninck, P.; Perrini, M.; Brubaker, C. E.; Messersmith, P. B.; Mazza, E.; Deprest, J.; Zimmermann, R.; Ehrbar, M.; Ochsenbein-Koelble, N., Mussel mimetic tissue adhesive for fetal membrane repair: initial in vivo investigation in rabbits. Eur. J. Obstet. Gynecol. Reprod. Biol. 2013, 171 (2), 240-245. 
51. Perrini, M.; Barrett, D.; Ochsenbein-Koelble, N.; Zimmermann, R.; Messersmith, P.; Ehrbar, M., A comparative investigation of mussel-mimetic sealants for fetal membrane repair. $J$. Mech. Behav. Biomed. 2016, 58, 57-64.

52. Shin, J.; Lee, J. S.; Lee, C.; Park, H.-J.; Yang, K.; Jin, Y.; Ryu, J. H.; Hong, K. S.; Moon, S.-H.; Chung, H.-M.; Yang, H. S.; Um, S. H.; Oh, J.-W.; Kim, D.-I.; Lee, H.; Cho, S.-W., Tissue Adhesive Catechol-Modified Hyaluronic Acid Hydrogel for Effective, Minimally Invasive Cell Therapy. Adv. Funct. Mater. 2015, 25 (25), 3814-3824. 